\title{
Liquisolid Tablets Formulation of Atorvastatin Calcium Using Polyethylene Glycol 400 as Solvent and Some Carrier Materials
}

\author{
Yulias Ninik Windriyati*, Matsniyyatul Badriyah, Diar Arum Kusumaningtyas, Rian Lesta Riesmalia
}

Department of Pharmaceutic and Pharmaceutical Technology, Faculty of Pharmacy, Universitas Wahid Hasyim, Semarang 50236

\begin{abstract}
Info Article
Submitted: $10-06-2020$

Revised: 06-10-2020

Accepted: $30-12-2020$

*Corresponding author

Yulias Ninik Windriyati

Email:

yninik@unwahas.ac.id

ABSTRACT

The dissolution of atorvastatin calcium need to be improved since included BCS Class II drugs with low solubility and high permeability, meaning that the dissolution affects the bioavailability of drugs. This research aimed to develop a formulation of a liquisolid tablet using PEG 400 as a solvent and some carrier materials in various compositions to increase the dissolution of atorvastatin calcium. Different formulations of liquisolid tablets were conducted using different quantities of carrier and coating material for adsorbing liquid solvent to produce a free-flowing and compressible powder. Avicel PH 101, Avicel PH 102, Neusilin US2 were employed as the carrier and Aerosil 200 as the coating material. A disintegrant and lubricant were then added to the formed liquisolid system and compressed into tablets by the direct compressing method. The liquisolid tablets were characterized for their tableting properties and possible drug-excipient interaction by XRD and FTIR analysis. The tableting characteristics of atorvastatin calcium liquisolid tablets were within the acceptable limits criteria. The dissolution of AA4 and NA1 liquisolid tablets was higher compared to marketed tablets. Based on the XRD and FTIR analysis, no interactions between drug and excipient.

Keywords: Atorvastatin calcium, Dissolution, Liquisolid tablets,
\end{abstract} Polyethylene Glycol 400

\section{INTRODUCTION}

Atorvastatin calcium is an oral antihyperlipidemic statin group that belongs to Class II of the Biopharmaceutical Classification System (BCS). The solubility is $\mathrm{pH}$-dependent i.e at $\mathrm{pH} 1.2$ is $0.02 \mathrm{mg} / \mathrm{mL}$ while increases to $1.23 \mathrm{mg} / \mathrm{mL}$ at $\mathrm{pH} 6.8$ (Kearney et al., 1993). The dose/solubility ratio for atorvastatin calcium is more than $250 \mathrm{~mL}$ for the $10 \mathrm{mg}$ dose at $\mathrm{pH} 1.2$ and dissolves in 250mL at pH 6.8 (Popy et al., 2012). The low oral bioavailability of atorvastatin calcium $(12-14 \%)$ is caused by low aqueous solubility in the gastric and high first-pass metabolism in the liver (Sonje et al., 2010). The dissolution profiles of atorvastatin calcium tablets which are currently marketed with generic and branded generic names vary per product and affect their bioavailability profiles (Oishi et al., 2011; Popy et al., 2012). Several techniques have been developed to increase the dissolution of atorvastatin calcium, including crystal modification (Gozali et al., 2014; Wicaksono et al., 2017a), co-grinding (Prabhu and Patravale, 2015), solid dispersion (Gozali et al.,
2015; Rodde et al., 2014; Panghal et al., 2014; Khan and Dehghan, 2011), lipid-based formulations such as micro and nanoemulsions (Chouksey et al., 2011; Snela et al., 2019; Kadu et al., 2011), and liquisolid technique (Gubbi and Jarag, 2010; Baskaran et al., 2016). Among all these methods the most promising method for enhancing dissolution for poorly soluble drugs is the formulation of liquisolid system. This technique is technically applicable at relatively low costs because it does not require a large amount of energy (e.g. for heating) and the absence of a volatile organic solvent. As a result, this technique can be implemented on an industrial scale (Lu et al., 2017; Yadav and Yadav, 2009)

Liquisolid technique is a technique of manufacturing tablets by dissolving their active ingredients in non-volatile solvents in order to be developed into suspension or liquid form and subsequently converted into a powder that is free-flowing, non-adherent, and readily compressible, with the addition of carriers and coatings (Spireas, 2002). 
Table I. Composition of liquisolid tablets with 10mg of atorvastatin calcium.

\begin{tabular}{cccccccccc}
\hline Code & Carrier- coating & $\mathbf{\%} \mathbf{C d}(\mathbf{w} / \mathbf{w})$ & $\mathbf{L f}$ & $\mathbf{W}$ & $\mathbf{R}$ & $\mathbf{Q}$ & $\mathbf{q}$ & SSG & Tablet weight $\mathbf{( g )}$ \\
\hline AA1 & & 10 & 0.123 & 100 & 20 & 800 & 40 & 94 & 1.043 \\
AA2 & Avicel PH 101- & 20 & 0.123 & 50 & 20 & 400 & 20 & 47 & 0.522 \\
AA3 & Aerosil & 30 & 0.123 & 33.3 & 20 & 280 & 14 & 33 & 0.363 \\
AA4 & & 10 & 0.123 & 100 & 20 & 800 & 40 & 94 & 1.043 \\
AA5 & Avicel PH 102- & 20 & 0.123 & 50 & 20 & 400 & 20 & 47 & 0.522 \\
AA6 & Aerosil & 30 & 0.123 & 33.3 & 20 & 280 & 14 & 33 & 0.363 \\
NA1 & & 10 & 0.334 & 100 & 20 & 300 & 15 & 21 & 0.438 \\
NA2 & Neusilin-Aerosil & 15 & 0.334 & 66.7 & 20 & 200 & 10 & 14 & 0.294 \\
NA3 & & 20 & 0.334 & 50 & 20 & 150 & 7.5 & 11 & 0.221 \\
\hline
\end{tabular}

\%Cd: amount of active substance in non-volatile solvent (expressed in percentage); Lf: liquid load factor (W/Q); W: weight of active substance and non-volatile solvent; R: excipient ratio (Q/q); Q: carrier; q: coating

Some of the non-volatile solvents are propylene glycol, polyethylene glycol (PEG) 200 and 400, glycerin, and polysorbate 80 . PEG 400 was selected to prepare liquid medication because the solubility of atorvastatin calcium in PEG 400 was $7.32 \% \mathrm{w} / \mathrm{w}$ (Gubbi and Jarag, 2010). In this work, the excipients like microcrystalline cellulose (PH 101 and 102) and Neusilin ${ }^{\circ}$ are used as carrier materials, Aerosil $®$ as a coating material, and sodium starch glycolate as superdisintegrant. The use of Neusilin $®$ with a large surface specific area and high porosity cause high adsorption capacity that is proven to be effective in maintaining drugs in the liquid state, thus increasing the dissolution (Vranikova and Gajdziok, 2013; Vraníková et al., 2015). The purpose of this research was to enhance the dissolution of atorvastatin calcium tablets using the liquisolid technique.

\section{MATERIAL AND METHODS}

Atorvastatin calcium trihydrate was obtained as a gift sample from Etercon Pharma, Polyethylene glycol 400, Avicel PH 101, Avicel PH 102, Wacker HDK, Sodium starch glycolate and Mg stearate (Bratachem), Neusilin US2 (Megasetia), $\mathrm{NaOH}$, and $\mathrm{KH}_{2} \mathrm{PO}_{4}$ (Merck). Branded generic tablets $10 \mathrm{mg}\left(\mathrm{AT}^{\circledR}\right)$, from a local pharmacy.

\section{Preparation for liquisolid tablets}

The mathematical model developed by Spireas (2002) was used to calculate the amount of material used for each liquisolid tablet formula

which contains $10 \mathrm{mg}$ of atorvastatin calcium, (Table I). Atorvastatin calcium was dispersed in PEG 400 with continuous mixing using pestle and mortar to obtain liquid medication. The binary mixture of carrier and coating material at a ratio 20:1 was added to the admixture of drug and solvent, blended at an approximate mixing rate to obtain homogeneously distribute the drug. The admixture is evenly spread as a uniform layer to allow drug dispersion to be adsorbed in the interior of powder particles. Dried with a binary mixture of a carrier and a coating made at a ratio of 20: 1 . A precompression analysis was carried out by testing the flowability to obtain the parameters of the repose angle and flow time. Besides, bulk and tapped density were also tested to determine the compressibility index. Subsequently, Sodium Starch Glycolate and Mg Stearate 1\%, functioning as a disintegrant, glidant, and a lubricant respectively, were added to the liquisolid powder that satisfied the criteria of good flowability before it was compressed into tablets.

\section{Evaluation of liquisolid tablets \\ Weight variation}

For each formulation, 20 tablets were selected randomly and weighed individually on an analytical balance. The average weight and standard deviation for each tablet formulation were calculated. Not more than two of the individual tablet weight deviate from the average weight by more than the percentage given in the USP Pharmacopeia, and none deviates by more than twice that percentage.

\section{Drug content uniformity}

In each formulation, 10 randomly selected tablets were evaluated for their drug content. The individual tablet was powdered, transferred into a 
beaker containing $100 \mathrm{~mL}$ phosphate buffer $\mathrm{pH} 6.8$. The solution was stirred for $1 \mathrm{~h}$, filtered, and the drug content was estimated spectrophotometrically (Shimadzu UV-1800 240V) using maximum wavelength at $24.6 \mathrm{~nm}$. The atorvastatin calcium concentration was determined based on the calibration curve previously built-in range 6$16 \mu \mathrm{g} / \mathrm{mL}$. The percentage of single-tablet drug content was determined and evaluated to the theoretical drug content (10mg).

\section{Hardness and friability}

Five tablets were taken randomly from the whole liquisolid systems and tested for their hardness with a hardness tester as to calculate the average values. On the other hand, friability testing was conducted using a friability tester according to USP regulations, and the testing was repeated 3 times. The percentage of weight loss was expressed as the friability value.

\section{Disintegration time}

The disintegration time of the liquisolid tablets was tested according to the testing procedure for uncoated tablets as outlined in USP regulations, and the test was performed 3 times. Based on the tests conducted, the disintegration time of those tablets was no longer than $15 \mathrm{~min}$.

\section{In vitro dissolution}

The dissolution test was conducted using a type II dissolution test apparatus (Electrolab TDT08L). The dissolution study was carried out in $900 \mathrm{~mL}$ of phosphate buffer at $\mathrm{pH} 6.8$ with a rotation speed of $75 \mathrm{rpm}$ and maintained at $37 \pm 0.5^{\circ} \mathrm{C}$ according to USP. The aliquot of $5 \mathrm{~mL}$ samples was withdrawn at $5,15,30,45$, and $60 \mathrm{~min}$ time intervals, respectively. Afterward, each sample was replaced with a fresh buffer medium in an equal quantity to maintain the sink conditions. The withdrawn sample was analyzed spectrophotometrically at $240.6 \mathrm{~nm}$. Six tablets from each liquisolid formulation were selected randomly for dissolution testing. The results were presented as mean values and standard deviations.

\section{X-ray powder diffraction}

The physical form of atorvastatin calcium in the liquisolid tablet was characterized using X-ray powder diffraction. The tablet was crushed to a fine powder and packed into a sample holder. The sample scanned using the instrument Shimadzu XRD-7000 with $\mathrm{Cu}$ as a target. The sample was analyzed in a $2 \theta$ angle range of $10-70^{\circ}$ with scanning step time $0.5 \mathrm{~s}$. The operating voltage and current settings were $400 \mathrm{kV}$ and $300 \mathrm{~mA}$ respectively. The X-ray diffractogram of major excipient and pure atorvastatin calcium powder was also obtained in the same way.

\section{Fourier Transform Infra-red spectrum analysis}

The spectrum of liquisolid tablet, major excipient, and pure atorvastatin calcium powder were recorded using a Perkin Elmer FTIR instrument with software version 10.4 by the $\mathrm{KBr}$ method. A baseline correction was made using dried potassium bromide. The spectrum were scanned in the wavelength region of $4000 \mathrm{~cm}^{-1}$ to $400 \mathrm{~cm}^{-1}$.

\section{RESULT AND DISCUSSION \\ Evaluation of prepared liquisolid powders}

The flow properties of the liquisolid powder are shown by different flow parameters. The results for flow rate, angle of repose, compressibility index (Table II). The obtained results suggest that all parameters were within the limits, and considered acceptable flowability. The liquisolid system of atorvastatin calcium was made using non-volatile solvent PEG 400 since it is soluble in that solvent. The carriers used materials like microcrystalline cellulose (Avicel PH 101 and PH 102) and magnesium aluminum metasilicate (Neusilin US2), which can adsorb solvent PEG 400, but still, have good flowability. About the coating, colloidal silicon dioxide (Aerosil) functioned as the material, as it is voluminous, thus appearing to be effective in adsorbing the solvent being used. These liquisolid powder can be effectively converted into liquisolid dosage form.

\section{Characteristic of liquisolid tablets}

The liquisolid tablets of atorvastatin calcium were characterized for average weight, drug content uniformity, hardness, friability, disintegration time, and obtained results (Table III). The tablet weight is found uniform due to a uniform size powder blend. A precise dose of drugs from one tablet to another is a basic quality for all pharmaceutical dosage forms. All of the liquisolid tablets contained atorvastatin calcium, with a range of $97-104 \%$. As suggested by the compendia, $10 \mathrm{mg}$ atorvastatin tablets should meet the uniformity of the active substance in the range $94.5-105 \%$ according to USP. 
Table II. Flow properties of atorvastatin calcium liquisolid system

\begin{tabular}{cccc}
\hline Code & Flow rate $(\mathbf{g} / \mathbf{s})$ & Angle of repose $\mathbf{(}^{\circ}$ ) & Carr's compressibility index $^{\text {AA1 }}$ \\
\hline AA2 & $49.85 \pm 1.04$ & $24.42 \pm 1.00$ & $13.92 \pm 1.57$ \\
AA3 & $26.56 \pm 1.54$ & $21.35 \pm 1.00$ & $18.37 \pm 0.58$ \\
AA4 & $28.53 \pm 0.79$ & $17.68 \pm 1.00$ & $17.67 \pm 0.58$ \\
AA5 & $35.36 \pm 1.52$ & $22.36 \pm 1.09$ & $14.17 \pm 0.38$ \\
AA6 & $26.43 \pm 0.46$ & $19.51 \pm 0.21$ & $16.53 \pm 0.62$ \\
NA1 & $16.95 \pm 0.80$ & $17.40 \pm 0.71$ & $18.07 \pm 0.19$ \\
NA2 & $15.38 \pm 0.80$ & $5.56 \pm 0.54$ & $15.33 \pm 1.15$ \\
NA3 & $15.87 \pm 0.66$ & $7.72 \pm 0.21$ & $15.00 \pm 1.00$ \\
\hline
\end{tabular}

Table III. Characteristics of atorvastatin calcium's liquisolid tablets

\begin{tabular}{|c|c|c|c|c|c|}
\hline Code & Weight (mg) & $\begin{array}{l}\text { Hardness } \\
\left(\mathrm{Kg} / \mathrm{cm}^{2}\right)\end{array}$ & $\begin{array}{c}\text { Friability } \\
(\%)\end{array}$ & $\begin{array}{l}\text { Disintegration } \\
\text { Time (minute) }\end{array}$ & $\begin{array}{c}\text { Active ingredients } \\
(\%)\end{array}$ \\
\hline AA1 & $1033.76 \pm 23.67$ & $6.28 \pm 0.23$ & $0.03 \pm 0.00$ & $3.25 \pm 0.01$ & 102.11 \\
\hline AA2 & $525.88 \pm 8.75$ & $6.14 \pm 0.34$ & $0.09 \pm 0.00$ & $2.63 \pm 0.15$ & 103.94 \\
\hline AA3 & $343.65 \pm 4.06$ & $5.91 \pm 0.27$ & $0.05 \pm 0.00$ & $2.12 \pm 0.02$ & 99.71 \\
\hline AA4 & $1066.67 \pm 9.66$ & $6.93 \pm 0.35$ & $0.02 \pm 0.00$ & $1.78 \pm 0.39$ & 99.28 \\
\hline AA5 & $531.44 \pm 3.51$ & $5.01 \pm 0.16$ & $0.03 \pm 0.01$ & $2.04 \pm 0.05$ & 101.86 \\
\hline AA6 & $352.74 \pm 2.17$ & $6.71 \pm 0.14$ & $0.06 \pm 0.04$ & $3.09 \pm 1.02$ & 104.00 \\
\hline NA1 & $439.70 \pm 1.72$ & $5.25 \pm 0.55$ & $0.61 \pm 0.04$ & $6.39 \pm 0.03$ & 97.68 \\
\hline NA2 & $292.25 \pm 1.59$ & $5.07 \pm 0.44$ & $0.51 \pm 0.11$ & $4.08 \pm 0.07$ & 103.51 \\
\hline NA3 & $221.20 \pm 2.02$ & $4.92 \pm 0.53$ & $0.38 \pm 0.24$ & $2.23 \pm 0.02$ & 102.97 \\
\hline
\end{tabular}

All the prepared formulation had hardness in the range of $4-7 \mathrm{~kg} / \mathrm{cm}^{2}$ and friability below $1 \%$. No tablet was broken or deformed. Since all prepared formulation met the standard criteria of hardness and friability, they are expected to show acceptable toughness and withstand abrasion during handling, packaging, and shipment. All the prepared formulation had a disintegration time below 15min (1-6min). Faster disintegration time indicates rapid release rates.

The tablet's characteristic data indicate that all the parameters were within the limits. The fulfillment of the liquisolid tablet's parameters was adherent to the fact that the formation of the liquisolid system was processed according to the tablet manufacturing procedure by the direct compressing method and using materials with good compressibility and compatibility. As the carriers as well as the main components in the liquisolid tablets, Microcrystalline cellulose (Avicel PH) and Neusilin are best known to have good characteristics of tablet forming materials. Coupled with Aerosil as the coating material, these two materials produced liquisolid powder that can be used as a free-flowing and easily compressible. The use of sodium starch glycolate as a disintegrant made the liquisolid tablets disintegrate faster, while magnesium stearate used as glidant and lubricant led to the formation of tablets with relatively low friability.

\section{In vitro dissolution studies}

The dissolution of the liquisolid tablets was carried out in a medium of phosphate buffer $\mathrm{pH} 6.8$, following that as an active ingredient, atorvastatin calcium is more soluble in a medium with that $\mathrm{pH}$ than with lower $\mathrm{pH}$. The dissolution profiles of the liquisolid tablets and the branded tablet of atorvastatin calcium (ATß) available in the market (Figure 1). The percentage drug release at the $30^{\text {th }}$ min was $83.66 \%$ for AA4 and $84.61 \%$ for NA1. Meanwhile, at $30 \mathrm{~min}$ the percentage drug release of $\mathrm{AT}^{\circledR}$ was $62.07 \%$. In the liquisolid tablets, the drug surface available for dissolution since a suspension of the drug in a non-volatile solvent is used for the preparation of this system. The presence of PEG 400 as a non-volatile solvent, which dispersed the active substance into finer and more soluble particles. After disintegration in the dissolving medium, the liquisolid particles of the 
drug suspended and dispersed molecularly. The surface area of the particle drug is much greater for dissolution.

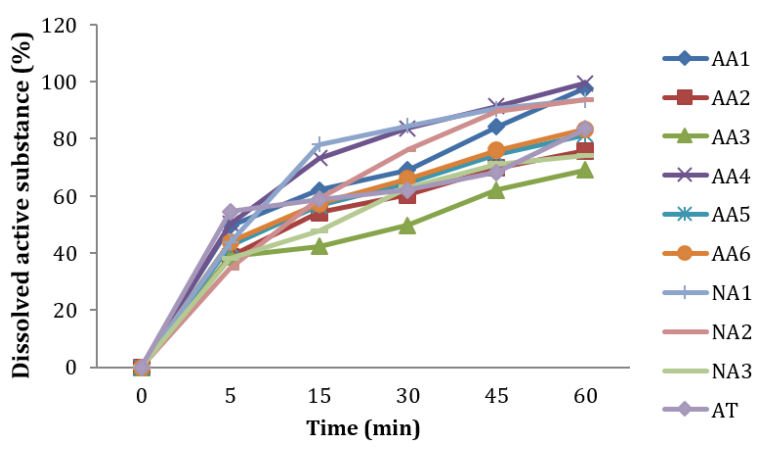

Figure 1. Dissolution profiles of atorvastatin calcium's liquisolid tablets and a branded tablet available on the market (AT ${ }^{\circledR}$ )

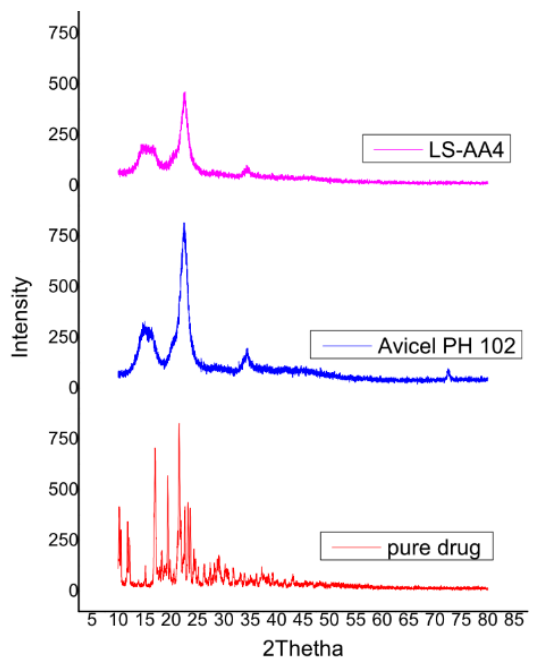

Figure 2. XRD diffractogram of the liquisolid tablet AA4, Avicel PH 102, and pure drug atorvastatin calcium powder.

\section{X-ray diffraction analysis}

Polymorphic changes in the active pharmaceutical ingredient are important since they might affect the dissolution and in line bioavailability. The polymorphic changes of atorvastatin calcium in liquisolid tablet is important to study to know there were changes compared to the initial powder. The results of the XRD diffractogram (Figure 2). The diffraction pattern of atorvastatin calcium showed numerous distinctive peaks indicates that the drug is in a highly crystalline state. Avicel PH 102 as a major excipient in AA4 tablet has a sharp diffraction peak at 22.37 (20). Whereas the liquisolid powder showed diffraction peaks at 22,40 (20) proof that the excipient stays in its state. However, the diffraction pattern of atorvastatin calcium in the liquisolid tablet showed the disappearance of sharp distinctive peaks indicates that the drug was solubilized in liquisolid formulation or entirely converted into an amorphous form. No crystalline state in the liquisolid system is perhaps the result of solubilization in the non-volatile solvent as a vehicle that is possibly adsorbed on the carrier and coating material. The amophization or solubilization of atorvastatin calcium may result in increased dissolution.

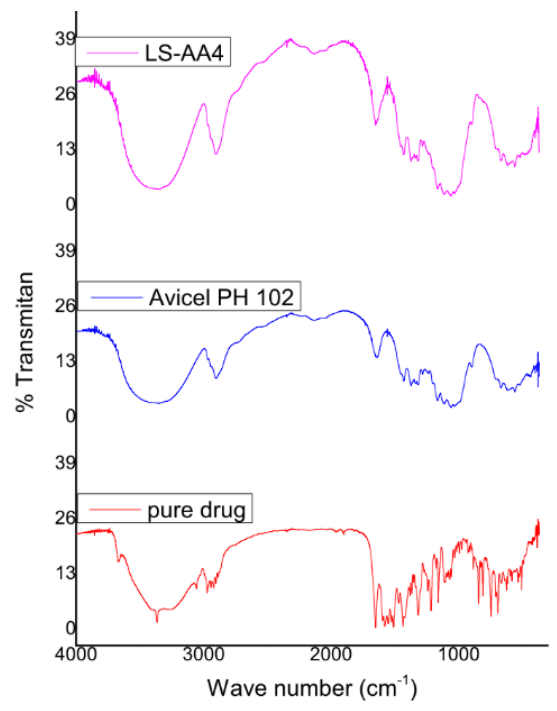

Figure 3. IR spectrum of the liquisolid tablet AA4, Avicel PH 102, and pure drug atorvastatin calcium powder.

\section{IR spectra analysis}

The IR spectral changes in formulation showed the chemical interaction between the drug and excipients. The spectral changes of atorvastatin calcium in liquisolid tablets are important to study to know there were changes compared to the initial powder. The characterization results by the FTIR spectroscopy (Figure 3). The characteristic peaks of $\mathrm{N}-\mathrm{H}$ stretching and aromatic $\mathrm{C}=\mathrm{O}$ stretching at $3365.08 \mathrm{~cm}-1$ and $1651.26 \mathrm{~cm}-1$ respectively. As seen in the IR spectrum, it is clear that the pure atorvastatin calcium powder used in the liquisolid tablet showed a typical functional group of atorvastatin calcium. The pattern of the liquisolid tablet AA4 showed the same characteristic peaks at 3350.3 and $1647.47 \mathrm{~cm}-1$ respectively, undergoes no chemical reaction with any of the excipients used in the preparation liquisolid formulation. 
There is a reduction in the intensity of the characteristic of absorption peaks of atorvastatin calcium in liquisolid tablets which might be attributed to the hydrogen bonding interaction of the amino and the carboxyl group of atorvastatin calcium with the hydroxyl group of PEG 400 as a vehicle. This resulted in drug dissolution enhancement as shown by dissolution data. The characterization results of the FTIR were in line with those of the XRD. It can be concluded that the enhancement in dissolution due to increasing wetting.

\section{CONCLUSION}

The results indicated that the liquisolid tablets of atorvastatin calcium can be prepared using some carrier material and non-volatile solvent like PEG 400. The liquisolid powder showed good flowability. The liquisolid tablets meet the criteria of hardness, friability, weight variation, and disintegration time. The dissolution testing showed increased drug release compared to the marketed product. XRD and IR spectrum suggest that there were no chemical interactions between the drug and excipients. The enhanced dissolution may be due to improved wetting and greater surface area of particles. The liquisolid formulation can then be developed as an alternative for the production of atorvastatin calcium tablets in the pharmaceutical industry.

\section{ACKNOWLEDGEMENT}

The authors are thankful to PT. Ethercon Pharma, Demak, for providing gift samples of the atorvastatin calcium and PT Phapros Tbk, Semarang for sodium starch glycolate.

\section{REFERENCES}

Baskaran, M., Talluri, K.B., Kuppusamy, G., Karri, V.V.S.R., and Kollipara, R. 2016). Formulation Development of Atorvastatin Calcium Tablets by Gel Liquisolid Compact Technique for Improving Solid State Stability and Dissolution Profile. Journal of Drug Research and Development. 2(4): 1-7.

Chouksey, R., Jain, A.K., Pandey, H., and Maithil, A. 2011. Development and bioavailability studies of atorvastatin nanoemulsion. International Journal of Pharmacy \& Life Sciences, 2(8): 982-988.

Gozali, D., Putra, A.F.C., and Sopyan, I. 2014. Pengaruh modifikasi kristal kalsium atorvastatin terhadap laju disolusi.
Bionatura-Jurnal Ilmu-imu Hayati dan Fisik. 16(2): 83-88.

Gozali, D., Wardhana, Y.W., and Shofa. 2015. Formulasi dan Evaluasi Tablet Dispersi Padat Kalsium Atorvastatin. Jurnal Pharmascience 2(2): 63-70.

Gubbi, S.R., \& Jarag, R. 2010. Formulation and characterization of atorvastatin calcium liquisolid compacts. Asian Journal of Pharmaceutical Sciences. 5(2): 50-60.

Kadu, P.J., Kushare, S.S., Thacker, D.D., and Gattani, S.G. 2011. Enhancement of oral bioavailability of atorvastatin calcium by self-emulsifying drug delivery systems ( SEDDS ). Pharmaceutical Development and Technology. 16(1): 65-74. https://doi.org/10.3109/10837450903499 333

Kearney, A.S., Crawford, L.F., Mehta, S.C., Radebaugh, G.W. 1993. The interconversion kinetics, equilibrium, and solubilities of the lactone and hydroxyacid forms of the HMGCoA reductase inhibitor CI-981. Pharmaceutical Research 10(10): 14611465.

Khan, F.N., and Dehghan, M.H.G. 2011. Enhanced Bioavailability of Atorvastatin Calcium from Stabilized Gastric Resident Formulation, AAPS PharmSciTech. 12(4): 1077-1086. https://doi.org/10.1208/s12249-0119673-3

Lu, M., Xing, H., Jiang, J., Chen, X., Yang, T., Wang, D., and Ding, P. 2017. Liquisolid technique and its applications in pharmaceutics. Asian Journal of Pharmaceutical Sciences, 12(2): 115-123. https://doi.org/10.1016/j.ajps.2016.09.007

Oishi, T. S., Nimmi, I., \& Islam, S.M.A. 2011. Comparative in vitro Bioequivalence Analysis of Some Generic Tablets of Atorvastatin, a BCS Class II Compound. Bangladesh Pharmaceutical Journal. 14(1): 61-66.

Panghal, D., Nagpal, M., Thakur, G.S., and Arora, S. 2014. Dissolution Improvement of Atorvastatin Calcium using Modified Locust Bean Gum by the Solid Dispersion Technique. 82: 177-191. https://doi.org/10.3797/scipharm.1301-23

Popy, F.A., Dewan, I., and Islam, S.M.A. 2012. Evaluation of In Vitro Equivalence for Tablets Containing the Poorly WaterSoluble Compound Atorvastatin, Dissolution Technology. 19(4): 30-33. 
Prabhu, P., and Patravale, V. 2016. Dissolution enhancement of atorvastatin calcium by cogrinding technique. Drug Delivery and Translational Research. 6(4): 380-391. https://doi.org/10.1007/s13346-0150271-x

Rodde, M. S., Divase, G. T., Devkar, T. B., \& Tekade, A. R. 2014. Solubility and Bioavailability Enhancement of Poorly Aqueous Soluble Atorvastatin : In Vitro, Ex Vivo, and In Vivo Studies, BioMed Research International 2014.

Snela, A., Jadach, B., Froelich, A., Skotnicki, M., Milczewska, K., Rojewska, M., and Lulek, J. 2019. Self-emulsifying drug delivery systems with atorvastatin adsorbed on solid carriers: formulation and in vitro drug release studies. Colloids and Surfaces A, 577(2019): 281-290. https://doi.org/10.1016/j.colsurfa.2019.05. 062

Sonje, V.M., Kumar, L. and Meena, C.L. 2010. Atorvastatin Calcium. in Kohli, G., Puri, V., \& Jain, R. (Eds). Profiles of Drug Substances Excipients and Related Methodology 1st ed., Vol. $35 . \quad$ Elsevier Inc. https://doi.org/10.1016/S18715125(10)35001-1

Spireas, S. 2002, Liquisolid System and Methods of
Preparing Same, Pharmaceutical Research, U.S.Pantent, 1 - 9

Vranikova, B., and Gajdziok, J. (2013). Liquisolid systems and aspects influencing their research and development, Acta Pharmaceutica 63: 447-465.

Vraníková, B., Gajdziok, J., \& Vetchý, D. 2015. Modern Evaluation of Liquisolid Systems with Varying Amounts of Liquid Phase Prepared Using Two Different Methods, BioMed Research International 2015.

Wicaksono, Y., Wisudyaningsih, B., and Siswoyo, T.A. 2017a. Enhancement of solubility and dissolution rate of atorvastatin calcium by co-crystallization. Tropical Journal of Pharmaceutical Research. 16(7): 14971502.

Wicaksono, Y., Wisudyaningsih, B., Widiarthi, F. O., and Siswoyo, T. A. 2017b. Thermodynamic and Thermomicroscopy Study of Atorvastatin Calcium-Succinic Acid Binary Mixtures, Indonesian Journal Chemistry. 17(3): 485-490. https://doi.org/10.22146/ijc.25089

Yadav, V. B. and Yadav, A.V. 2009. Liquisolid granulation technique for tablet manufacturing: an overview. Journal of Pharmacy Research 2(4): 670-674. 